\title{
Substantial improvement in immune thrombocytopenic purpura associated with T-cell/histiocyte-rich B-cell lymphoma treated with chemotherapy: A case report
}

\author{
TAKATSUGU OGATA ${ }^{1}$, YOSHIMITSU SHIMOMURA ${ }^{2}$, DAISUKE YAMASHITA ${ }^{3}$, \\ YUKIHIRO IMAI $^{3}$ and TAKAYUKI ISHIKAWA ${ }^{1}$ \\ Departments of ${ }^{1}$ Medical Oncology, ${ }^{2}$ Hematology and ${ }^{3}$ Pathology, Kobe City Medical Center \\ General Hospital, Kobe City Hospital Organization, Kobe, Hyogo 650-0047, Japan
}

Received January 18, 2019; Accepted February 22, 2019

DOI: $10.3892 / \mathrm{mco} .2019 .1816$

\begin{abstract}
Immune thrombocytopenic purpura (ITP) is characterized by antibody and immune platelet destruction, occasionally leading to life-threatening hemorrhage. ITP is a frequent complication of chronic lymphoid leukemia, but is rarely associated with diffuse large B-cell lymphoma (DLBCL). We herein describe a case of ITP associated with T-cell/ histiocyte-rich B-cell lymphoma (T/HRBCL), which is a rare variant of DLBCL. A 54-year-old man presented with fever, multiple lymphadenopathies, petechial purpura and intraoral mucosal hemorrhage. Laboratory data revealed thrombocytopenia, normal white blood cell count, mild anemia, no active viral infections, and no autoimmune antibodies. Multiple lymphadenopathies were observed on computed tomography. A bone marrow biopsy revealed minor hypercellularity with increased number of megakaryocytes; however, there were no pathological cells or phagocytic cells. The patient was diagnosed with ITP; concurrently, he was also diagnosed with T/HRBCL via lymph node biopsy, and was treated accordingly with a chemotherapeutic regimen comprising rituximab, cyclophosphamide, doxorubicin, vincristine and prednisolone. Prompt reduction in the size of the superficial lymph nodes and an increase of the platelet count were observed simultaneously. To the best of our knowledge, this is the first report of
\end{abstract}

Correspondence to: Dr Yoshimitsu Shimomura, Department of Hematology, Kobe City Medical Center General Hospital, Kobe City Hospital Organization, 2-1-1 Minatojima-Minamimachi, Chuo-ku, Kobe, Hyogo 650-0047, Japan

E-mail: shimomura_0119@yahoo.co.jp

Abbreviations: CD, cluster of differentiation; DLBCL, diffuse large B-cell lymphoma; ITP, immune thrombocytopenic purpura; NHL, non-Hodgkin lymphoma; T/HRBCL, T-cell/histiocyte-rich B-cell lymphoma

Key words: immune thrombocytopenic purpura, T-cell/histiocyterich B-cell lymphoma, chemotherapy, R-CHOP, recurrence
T/HRBCL complicated by ITP. The findings strongly suggest a causative association between ITP and T/HRBCL.

\section{Introduction}

Immune thrombocytopenic purpura (ITP) is characterized by antibody- and immune-precipitated platelet destruction, occasionally causing life-threatening hemorrhage. ITP is a frequent complication of hematological malignancies, particularly chronic lymphoid leukemia (1); however, it is less common in non-Hodgkin lymphoma (NHL), affecting only $0.76 \%$ of the patients (2). Thus, the etiology and treatment of NHL-associated ITP have not been clearly determined, although this is a potentially life-threatening condition that is difficult to manage.

Only 10 cases of diffuse large B-cell lymphoma (DLBCL), which is the most common type of NHL, complicated by ITP have been reported to date (2). T-cell/ histiocyte-rich B-cell lymphoma (T/HRBCL) is an uncommon variant of DLBCL characterized by a limited number of atypical B cells in a background of abundant $T$ cells and histiocytes $(3,4)$. A case of T/HRBCL complicated by symptoms mimicking autoimmune disease was recently reported (5). We herein describe what is, to the best of our knowledge, the first case of T/HRBCLassociated ITP successfully treated by chemotherapy.

\section{Case report}

A 54-year-old man presented to Kobe City Medical Center General Hospital (Kobe, Japan) in May 2017 with a fever of $38.9^{\circ} \mathrm{C}$, bilateral cervical and right axillary lymphadenopathies, petechial purpura on the upper and lower limbs and intraoral mucosal hemorrhage. The patient reported a history of fever and lymphadenopathy that started 1 month prior to hospitalization, and he was admitted to our hospital for thorough examination and treatment. The patient had no symptoms indicative of collagen disease, such as skin rash or joint pain. His liver and spleen were not palpable. The laboratory data on admission are summarized in Table I. Briefly, complete blood count and biochemical tests revealed the following: Hemoglobin, $12.2 \mathrm{~g} / \mathrm{dl}$; platelet count, $0.5 \times 10^{9} / 1$; 


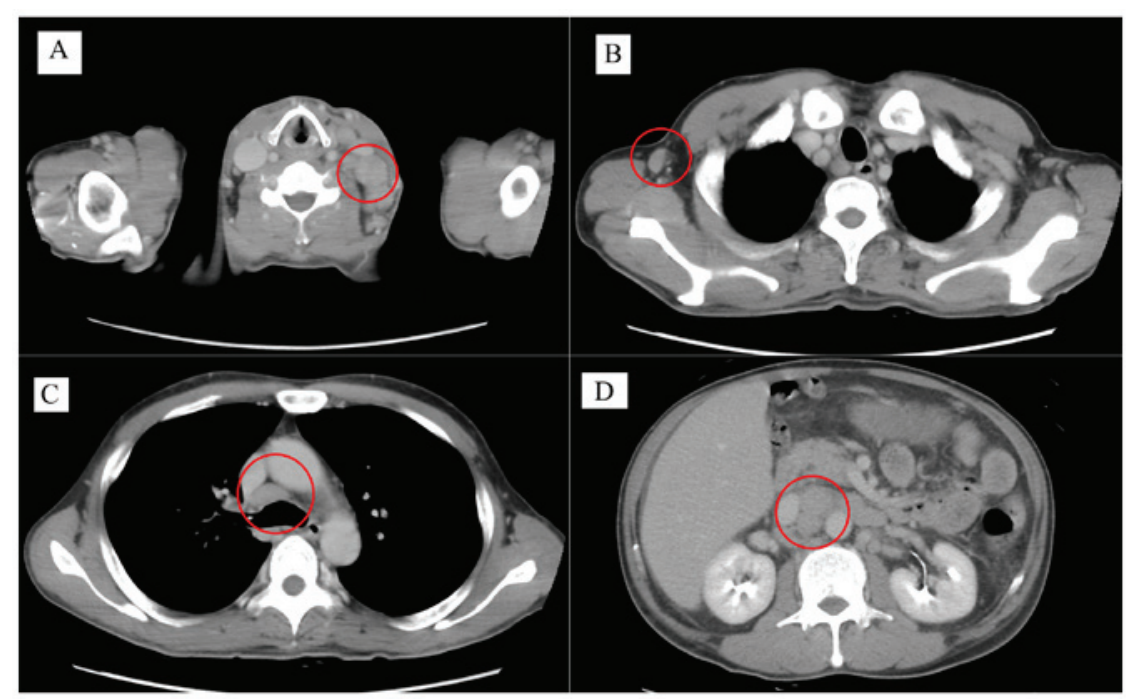

Figure 1. Computed tomography images acquired prior to treatment. (A) Left cervical lymphadenopathy, $25 \mathrm{~mm}$; (B) right axillary lymphadenopathy, $15 \mathrm{~mm}$; (C) mediastinal lymphadenopathy, $19 \mathrm{~mm}$; (D) paraaortic lymphadenopathy, $20 \mathrm{~mm}$.
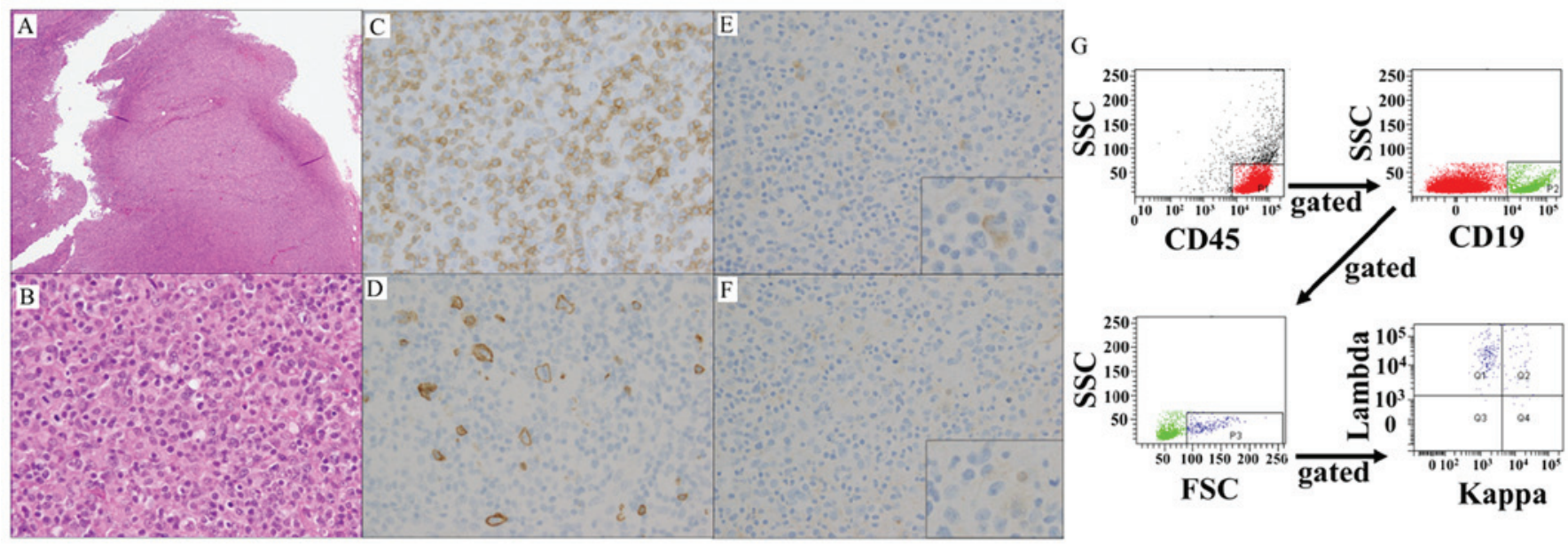

Figure 2. Histological findings of a biopsy specimen from a right axillary lymph node. (A) Hematoxylin and eosin (H\&E) staining, magnification, $\mathrm{x} 4$. The lymph node structure was almost completely effaced by a diffuse infiltrate. (B) H\&E staining; magnification, $x 40$. A small number of scattered large atypical cells were found among numerous mature lymphoid cells. (C) Immunostaining for CD3; magnification, x40. Atypical cells were negative for CD3. (D) Immunostaining for CD20; magnification, $x 40$. CD20 was expressed on atypical cells. (E) Immunostaining for lambda ( $\lambda$ ) light chain; magnification, $x 40$. $\lambda$ was expressed on CD20-positive atypical cells. (F) Immunostaining for kappa ( $\kappa$ ) light chain; magnification, $x$ 40. Infiltrating large cells were negative for $\kappa$ light chain. (G) Flow cytometric analysis of the lymph node. Infiltrating cells which gated $\mathrm{CD} 45^{+}, \mathrm{CD} 19^{+}$and high forward scatter were positive for $\lambda$ and negative for $\kappa$ light chain.

reticulated platelets, 59\%; white blood cell count, 10.1×10 $/ 1$; lactate dehydrogenase (LDH), $315 \mathrm{U} / 1$; soluble interleukin-2 receptor, $25,045 \mathrm{U} / \mathrm{ml}$; platelet-associated immunoglobulin $\mathrm{G}$, $462.2 \mathrm{ng} / 10^{7}$ cells; antinuclear antibody, negative; and EpsteinBarr virus antibody and human immunodeficiency virus, negative. Computed tomography examination revealed bilateral cervical $(25 \mathrm{~mm})$, bilateral axillary $(15 \mathrm{~mm})$, mediastinal $(19 \mathrm{~mm})$ and para-aortic $(20 \mathrm{~mm})$ lymphadenopathies (Fig. 1). A bone marrow biopsy revealed mild hypercellularity, with an increase in the number of megakaryocytes; however, pathological lymphocytes or phagocytes were not identified. Flow cytometric analysis and molecular analysis confirmed the absence of clonal malignant cell invasion. The suspected diagnosis was immune thrombocytopenic purpura (ITP), based on the thrombocytopenia, normal white blood cell count, mild anemia, increase in reticulated platelets, and lack of evidence of malignant cell invasion, hemophagocytic syndrome, or other cause of thrombocytopenia. Intravenous immunoglobulins were administered, but did not improve the platelet count. A biopsy of a right axillary lymph node was performed and the lymph node structure was found to be almost completely effaced by a diffuse infiltrate (Fig. 2A). A small number of scattered large atypical cells were found among numerous mature lymphoid cells (Fig. 2B). Immunohistochemical examination revealed expression of CD20 on the large malignant cells and CD3 on the small cells of the background. CD30, CD15 and Epstein-Barr virus early small ribonucleic acids were absent in both the large and small lymphocytes (Fig. 2C and $\mathrm{D})$. The infiltrating large cells were positive for $\lambda$ but negative for $\kappa$ light chain (Fig. 2E-G). Immunoglobulin heavy 
Table I. Patient's laboratory data on admission.

\begin{tabular}{|c|c|c|}
\hline Hematology & $\begin{array}{c}\text { Patient } \\
\text { data }\end{array}$ & $\begin{array}{l}\text { Normal } \\
\text { range }\end{array}$ \\
\hline White blood cell count $(/ \mu 1)$ & 10,100 & $3,900-9,800$ \\
\hline Neutrophils (\%) & 54.0 & \\
\hline Eosinophils (\%) & 0.5 & \\
\hline Basophils (\%) & 0.0 & \\
\hline Monophils (\%) & 11.0 & \\
\hline Lymphocytes (\%) & 33.0 & \\
\hline Other $(\%)$ & 1.5 & \\
\hline Red blood cell count $\left(\mathrm{x} 10^{4} / \mu \mathrm{l}\right)$ & 398 & $410-570$ \\
\hline Hemoglobin (g/dl) & 12.2 & $13.4-17.6$ \\
\hline Platelet count $\left(\mathrm{x} 10^{4} / \mu 1\right)$ & 0.5 & $13.0-37.0$ \\
\hline Reticulated platelets (\%) & 59 & $0-10$ \\
\hline \multicolumn{3}{|l|}{ Coagulation } \\
\hline PT $(\%)$ & 72.1 & $80.0-125.0$ \\
\hline APTT (sec) & 37.1 & 24.3-38.9 \\
\hline D-dimer $(\mu \mathrm{g} / \mathrm{ml})$ & 17.90 & $<1.00$ \\
\hline Fibrinogen (mg/dl) & 149 & $180-320$ \\
\hline \multicolumn{3}{|l|}{ Tumor marker } \\
\hline sIL-2R (U/ml) & 25,045 & $122-496$ \\
\hline \multicolumn{3}{|l|}{ Biochemistry } \\
\hline Total protein $(\mathrm{g} / \mathrm{dl})$ & 5.4 & $6.5-8.5$ \\
\hline Albumin (g/dl) & 3.1 & $3.9-4.9$ \\
\hline Total bilirubin (mg/dl) & 1.2 & $0.2-1.2$ \\
\hline $\operatorname{AST}(\mathrm{U} / \mathrm{l})$ & 55 & $8-40$ \\
\hline $\operatorname{ALT}(\mathrm{U} / \mathrm{l})$ & 29 & $8-40$ \\
\hline LDH (U/l) & 315 & $120-250$ \\
\hline BUN (mg/dl) & 15.3 & $8.0-20.0$ \\
\hline Creatinine (mg/dl) & 0.66 & $0.60-1.10$ \\
\hline $\mathrm{Na}(\mathrm{mEq} / \mathrm{l})$ & 135 & $136-148$ \\
\hline $\mathrm{K}(\mathrm{mEq} / \mathrm{l})$ & 4.0 & $3.5-5.3$ \\
\hline $\mathrm{Ca}(\mathrm{mg} / \mathrm{dl})$ & 8.3 & $8.0-10.0$ \\
\hline CRP (mg/dl) & 0.16 & $0.00-0.50$ \\
\hline \multicolumn{3}{|l|}{ Immunological } \\
\hline PA-IgG (ng/107 cells) & 462.2 & $<30.2$ \\
\hline
\end{tabular}

ALT, alanine aminotransferase; AST, aspartate aminotransferase; APTT, activated partial thromboplastin time; BUN, blood urea nitrogen; $\mathrm{Ca}$, calcium; CRP, C-reactive protein; $\mathrm{K}$, potassium; $\mathrm{LDH}$, lactate dehydrogenase; Na, sodium; PA-IgG, platelet-associated immunoglobulin G; PT, prothrombin time; sIL-2R, soluble interleukin-2 receptor.

chain rearrangement was not detected, and the karyotype of the lymphoma cells was $46, X Y$. Therefore, the patient was diagnosed with T/HRBCL of Ann Arbor stage IIIB and an International Prognostic Index of 2 points (stage and LDH).

The patient received prednisolone $(100 \mathrm{mg})$ from the day of biopsy until confirmation of the pathological diagnosis; thereafter, he was treated with the R-CHOP regimen, which consisted of rituximab $\left(375 \mathrm{mg} / \mathrm{m}^{2}\right)$, cyclophosphamide $\left(750 \mathrm{mg} / \mathrm{m}^{2}\right)$, doxorubicin $\left(50 \mathrm{mg} / \mathrm{m}^{2}\right)$ and vincristine

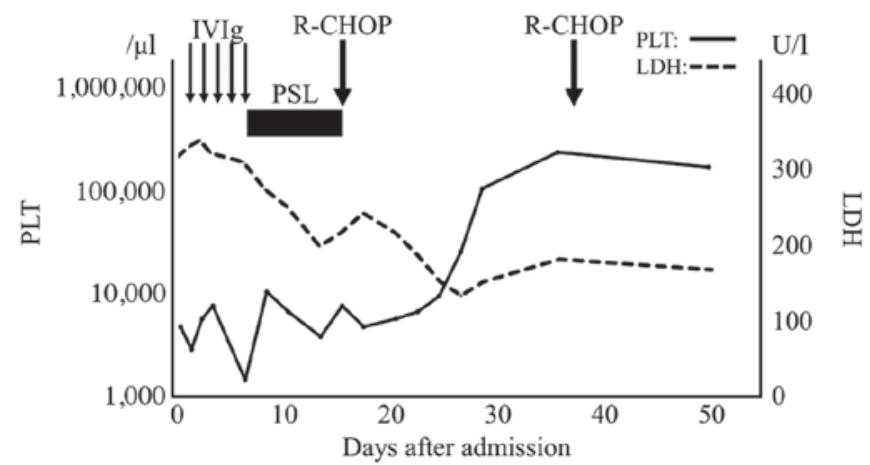

Figure 3. Schematic presentation of the clinical course of the patient. IVIg, intravenous immunoglobulin G; LDH, lactate dehydrogenase; PLT, platelet; PSL, prednisone; R-CHOP, combination chemotherapy with rituximab, cyclophosphamide, doxorubicin, vincristine and prednisone.

[1.4 $\mathrm{mg} / \mathrm{m}^{2}(\max 2 \mathrm{mg} /$ body)] on day 1 , and prednisolone (100 mg/body) on days $1-5$. Prompt reduction of the size of the superficial lymph nodes was observed, whereas the platelet count started to increase at 10 days and normalized at 36 days after chemotherapy initiation (Fig. 3). Treatment was terminated after three cycles due to financial difficulties.

The patient visited our hospital again 10 months after treatment interruption due to fever, fatigue, lymphadenopathies and bleeding tendency. The laboratory data were similar to those at first presentation: Hemoglobin, $10.0 \mathrm{~g} / \mathrm{dl}$; platelet count, $0.1 \times 10^{9} / 1$; white blood cell count, $5.4 \times 10^{9} / 1$; LDH, 264 $\mathrm{U} / 1$; ferritin, $615 \mathrm{ng} / \mathrm{ml}$ (normal range, 33.8-369.1); and soluble interleukin-2 receptor, 25,972 U/ml. Computed tomography examination revealed diffuse lymphadenopathy. Re-biopsy was not performed due to the strong bleeding tendency and the need for urgent treatment. The patient received three cycles of R-CHOP and two cycles of rituximab $\left(375 \mathrm{mg} / \mathrm{m}^{2}\right)$ and carboplatin (area under the curve $=5$ ) on day 1 , plus ifosphamide $\left(1,700 \mathrm{mg} / \mathrm{m}^{2}\right)$ and etoposide $\left(100 \mathrm{mg} / \mathrm{m}^{2}\right)$ on days $1-3$ (R-ICE regimen).

The platelet count was increased and this increase was sustained after the first chemotherapy, whereas positron emission tomography after the treatment revealed complete remission of T/HRBCL. Further treatment was not carried out because of a treatment refusal.

\section{Discussion}

We herein report the first case of T/HRBCL-associated ITP that substantially improved with chemotherapy. The patient initially received a standard treatment for ITP that failed to improve the thrombocytopenia, but he achieved complete remission of ITP following administration of R-CHOP chemotherapy, indicating the efficacy of R-CHOP for patients with T/HRBCL-associated ITP. In addition, the reproducibility at recurrence suggested an association between T/HRBCL and ITP.

No specific criteria for the diagnosis of ITP have been established to date, and diagnosing patients is a process of exclusion. Drugs, infection, autoimmune disease, liver diseases and bone marrow diseases may cause thrombocytopenia. In the present case, the patient had no diseases that 
may have caused the thrombocytopenia except for T/HRBCL, and there was no bone marrow invasion or hemophagocytic syndrome that may result in thrombocytopenia. In addition to these observations at the time of first presentation, the patient had the same presentation at the time of recurrence. It is difficult to exclude disseminated intravascular coagulation, but the clinical presentation of this patient was different from previous reports in terms of very low platelet count at presentation, no organ abnormalities and low-intermediate IPI score $(6,7)$. Thus, the patient was diagnosed with T/HRBCLassociated ITP, although there was a possibility of complicated disseminated intravascular coagulation. This diagnosis was supported by the observed platelet recovery as the lymphoma remitted.

ITP is often associated with chronic lymphoid leukemia, but it is less common in patients with malignant lymphomal $(1,2)$, with only 10 cases of DLBCL-associated ITP reported to date (2). T/HRBCL is an uncommon variant of $\operatorname{DLBCL}(3,4)$, and patients with T/HRBCL are more likely to develop B symptoms and respond to R-CHOP therapy, with an overall response rate of $56-63 \%(8-11)$. Although the exact mechanism underlying the association of thrombocytopenia and malignant lymphoma is unknown, there are certain possible hypotheses. One such hypothesis is that anti-platelet antibodies are produced by lymphoma cells. This is supported by findings of platelet antibody production by DLBCL cells during ITP (12). In the present case, the level of platelet-associated immunoglobulin $\mathrm{G}$ was decreased after R-CHOP treatment, which supports this hypothesis. In this case of T/HRBCL complicated by symptoms mimicking systemic lupus erythematosus, upregulation of innate immune molecules, including interleukin-6, interleukin-8 and growth-regulated oncogene, induced multiple autoimmune reactions that ultimately resulted in symptoms similar to those of systemic lupus erythematosus (5). Unfortunately the cytokine profiles in the present case were not evaluated, but $\mathrm{T} / \mathrm{HRBCL}$-induced innate immunity may have been associated with the development of ITP.

The standard first-line treatment for severe ITP includes corticosteroids and/or intravenous immunoglobulin. However, such treatment has been previously reported to be ineffective for DLBCL-associated ITP. Uchiyama et al reported a case of DLBCL-associated ITP in which standard ITP therapy was not effective, but the patient's platelet count was improved after R-CHOP (13). Berrang et al reported a case of isolated DLBCL complicated by ITP. The patient was treated with radiotherapy, and his platelet count also improved (14). These cases suggest that antitumor therapies, such as chemotherapy and radiotherapy, are more effective for NHL-ITP. Similarly, intravenous immunoglobulin administration failed to improve the thrombocytopenia in our patient, but he responded to R-CHOP therapy at first presentation and recurrence. Hence, chemotherapy should be further evaluated and considered as first-line therapy for T/HRBCL- and DLBCL-associated ITP.

\section{Acknowledgements}

The authors would like to thank the medical and nursing staff at the Kobe City Medical Centre General Hospital.

\section{Funding}

No funding was received.

\section{Availability of data and materials}

All data analyzed during the present study are included in this published manuscript.

\section{Authors' contribution}

TO, YS and TI contributed to the diagnosis and wrote the manuscript. DY and YI performed the pathological examination. All the authors have read and approved the final version of this manuscript.

\section{Ethics approval and consent to participate}

The requirement for review of this case report was waived by the Institutional Review Board of our hospital.

\section{Patient consent for publication}

Written informed consent was obtained from the patient regarding the publication of the case details and any associated images.

\section{Competing interests}

The authors declare that they have no competing financial or non-financial interests to disclose.

\section{References}

1. Váróczy L, Gergely L, Zeher M, Szegedi G and Illés A: Malignant lymphoma-associated autoimmune diseases - a descriptive epidemiological study. Rheumatol Int 22: 233-237, 2002.

2. Hauswirth AW, Skrabs C, Schützinger C, Raderer M, Chott A, Valent P, Lechner K and Jäger U: Autoimmune thrombocytopenia in non-Hodgkin's lymphomas. Haematologica 93: 447-450, 2008.

3. Abramson JS: T-cell/histiocyte-rich B-cell lymphoma: Biology, diagnosis, and management. Oncologist 11: 384-392, 2006.

4. Swerdlow SH, Campo E, Pileri SA, Harris NL, Stein H, Siebert R, Advani R, Ghielmini M, Salles GA, Zelenetz AD, et al: The 2016 revision of the World Health Organization classification of lymphoid neoplasms. Blood 127: 2375-2390, 2016.

5. Wu B and Cheng Y: Upregulation of innate immune responses in a $\mathrm{T}$ cell/histiocyte-rich large $\mathrm{B}$ cell lymphoma patient with significant autoimmune disorders mimicking systemic lupus erythematosus. Ann Hematol 93: 353-354, 2014.

6. Asakura H, Takahashi H, Tsuji H, Matsushita T, Ninomiya H, Honda G, Mimuro J, Eguchi Y, Kitajima I and Sakata Y: Post-marketing surveillance of thrombomodulin alfa, a novel treatment of disseminated intravascular coagulation - safety and efficacy in 1,032 patients with hematologic malignancy. Thromb Res 133: 364-370, 2014.

7. Chi S and Ikezoe T: Disseminated intravascular coagulation in non-Hodgkin lymphoma. Int J Hematol 102: 413-419, 2015.

8. Aki H, Tuzuner N, Ongoren S, Baslar Z, Soysal T, Ferhanoglu B, Sahinler I, Aydin Y, Ulku B and Aktuglu G: T-cell-rich B-cell lymphoma: A clinicopathologic study of 21 cases and comparison with 43 cases of diffuse large B-cell lymphoma. Leuk Res 28: 229-236, 2004

9. Wang J, Sun NCJ, Chen YY and Weiss LM: T-cell/histiocyterich large B-cell lymphoma displays a heterogeneity similar to diffuse large B-cell lymphoma: A clinicopathologic, immunohistochemical, and molecular study of 30 cases. Appl Immunohistochem Mol Morphol 13: 109-115, 2005. 
10. Bouabdallah R, Mounier N, Guettier C, Molina T, Ribrag V, Thieblemont C, Sonet A, Delmer A, Belhadj K, Gaulard P, et al T-cell/histiocyte-rich large B-cell lymphomas and classical diffuse large B-cell lymphomas have similar outcome after chemotherapy: A matched-control analysis. J Clin Oncol 21: 1271-1277, 2003.

11. Achten R, Verhoef G, Vanuytsel L and De Wolf-Peeters C: T-cell/histiocyte-rich large B-cell lymphoma: A distinct clinicopathologic entity. J Clin Oncol 20: 1269-1277, 2002.

12. Tan J, Wei J, Ni X and Zhou J: Immune thrombocytopenic purpura occurred prior to multiple extranodal diffuse large B cell lymphoma. Platelets 22: 81-83, 2011.
13. Uchiyama M, Sato K and Ikeda T: Diffuse large B-cell lymphoma complicated with autoimmune thrombocytopenia. Intern Med 50: 1215-1218, 2011.

14. Berrang T, Holloway C, Hart J, Yee A, Berry B and Kotb R: Successful treatment of non-Hodgkin lymphoma associated immune thrombocytopenia with involved field radiotherapy. Hematol Oncol 31: 218-220, 2013. 